\title{
Analysis of dream contents by scaled and rated measurements
}

\author{
JEAN-MICHEL GAILLARD' AND MARC PHELIPPEAU
}

\author{
From the Clinique Psychiatrique, University of Geneva
}

SYNOPSIS The study was undertaken in order to test a dream-rating scale and to propose some modifications, especially for use in laboratory situations, where the effect of a given experimental factor is to be assessed on mental activity in sleep. Dreams collected from normal subjects under EEG monitoring were analysed in detail in order to establish definitions for each rating point of each dimension of the rating scale. The scoring of a second set of dreams by two judges using this scale resulted in an inter-rater agreement significantly above the level of chance agreement.

\section{INTRODUCTION}

Measurement of dream-content is not an easy problem. There are numerous factors in the recall of dreams which may influence their content and even their definition (Kramer et al. 1975). The first requirement is a precise definition of what is to be measured. Dream-content is generally understood as an oral or written report of any mental material associated with any stage of sleep. For the purpose of this study, we shall adopt a somewhat more restrictive definition. We shall call a dream any verbal material reported by a subject under EEG monitoring, when he is artificially wakened, and which is related to something experienced in the earlier part of sleep and containing at least one significant word. A significant word is, for us, any substantive, adjective or verb, except 'to be' and 'to have', and excluding any word describing the mental state of the subject, such as "I am not sure', 'I believe it was', 'I remember', 'I have thoughts in mind'.

A second problem is the measurement of this material. Several dream-rating scales have been described, designed specifically for one or several studies (Foulkes et al. 1966; Molinari \& Foulkes, 1969), or more generally (Whitman et al. 1961 ; Hall \& van de Castle, 1966; Hauri et al. 1967). Some rating systems are descriptive and concerned mainly with the manifest content of

\footnotetext{
1 Address for correspondence: Dr J.-M. Gaillard, Clinique de Bel-Air, CH-1225 Chene-Bourg, Switzerland.
}

dreams (Hall \& van de Castle, 1966), whereas others are based on theoretical considerations resting on a theory of personality (Gottschalk et al. 1960; Sheppard, 1969). We shall focus here on a general, descriptive, empirical approach to the problem.

The most complete rating system is the one of Hall \& van de Castle (1966). In addition to its accuracy, it is, to our knowledge, the only system providing normative data. However, the use of the entire system is relatively time-consuming. It may be desirable to have at our disposal a simpler and reasonably reliable system allowing us to screen the material of an experiment and to cover the most important features of dreams.

The rating scale described by Hauri et al. (1967) goes some way towards meeting requirements of simplicity, universality, completeness and independence from a personality theory. It includes an important feature, namely a correlation between variables indexing the dimensions of the dream. The items of the scale overlap reasonably little, since no correlation is greater than $0 \cdot 21$, most of them being smaller than $0 \cdot 10$. However, the mode of calculation of inter-scorer agreement is not specified; it is thus difficult to estimate the real significance of the inter-rater correlation indicated in the paper; it also lacks a precise definition of each point of the different items. We have noted, in a pilot application to other material, that its reliability was not very good in the absence of such definitions.

The present study explores the reliability of 
this scale when it is supplemented by definitions for every rating point. The calculation of agreement indexes and their comparison among items served as a guide-line to reconsider, state precisely and extend the set of definitions which will be presented in the appendix.

\section{MATERIALS AND METHODS}

The material for this study was taken from an experiment on the effects of a benzodiazepine compound on dream-content. The subjects were unpaid volunteers, 6 women and 2 men, aged from 22 to 37 . Six of them were students at a local nurses' school. All were physically and mentally healthy; none of them was involved in any kind of psychotherapeutic or psychoanalytic treatment. The seventh subject was a television technician, the eighth a secretary working at the clinic. None of the subjects was involved in other dream or sleep experiments.

After one night of habituation, recordings from all subjects were taken in the laboratory in accord with standard procedures for 6 nights $(2 \times 3$ nights). They were awakened in sleep stage 2 or in REM sleep, approximately in a balanced order, several times nightly. The entire experiment consisted of 207 awakenings, yielding 140 dreams according to the definition given above. Of these, 8 dream-contents were discarded since they were obtained in a poorly defined stage of sleep, mostly stage 1. The results are based on 132 dreams, 30 in stage 2 and 102 in REM sleep.

Awakenings were made by one of the authors (M.P.) to whom only one of the subjects was known personally. REM sleep awakenings were scheduled at least $5 \mathrm{~min}$ after the beginning of the REM phase, and stage 2 awakenings after at least $20 \mathrm{~min}$ in this stage. The experimenter entered the room, gently touched the arm of the subject, and asked: 'Were you dreaming?' This question was chosen instead of 'Was something going through your mind?' because it is more direct and closer to common sense. Before the beginning of the experiment, however, subjects were instructed that by dreaming was meant any mental content or mental activity, and that it was equally important to know their thoughts or their visual imagery. After the initial query, the experimenter allowed the subject to speak freely, stating only 'yes' by way of reinforcement. This part of the dream-content was called the spontaneous report. When the subject stopped speaking, and seemed to have nothing to add, the experimenter asked for further details; the principal questions, unless the responses were obvious from the spontaneous report, concerned the presence of the dreamer in the dream, the presence of other characters, the activity of the dreamer, the feeling of bizarreness in the dream, its pleasantness or unpleasantness, the presence of colours, the content of conversations, and the time of the dream with respect to the awakening ('Just before?' or 'How long before?'). These reports were then typed and randomized. Reports containing at least one significant word (see introduction for the definition) were independently scored by two judges using the rating scale of Hauri et al. (1967), with each item divided into 6 points, and each point precisely defined in advance on the basis of a pilot experiment. A final rating was eventually agreed by discussion between the two judges on the basis of their previous ratings.

For statistical calculations of inter-scorer reliability, the weighted Kappa test was used (Cohen, 1960, 1968; Fleiss et al. 1969). This test is an index agreement basically for use with nominal scales, providing the possibility of giving maximum weight to perfect agreement, and a decreasing weight in proportion to the extent of disagreement. Furthermore this test, whose error may be calculated and whose theoretical distribution is approximately normal, allows of a comparison between the agreement for different items. It is thus possible to test for statistical significance not only the agreement expected by chance alone, but to compare the agreement for different items.

On the basis of the agreement indexes, the final step of our work was to re-examine the definitions of the rating points, using all the material collected in this study, to provide better anchor points and to make some slight changes in the scale originally presented by Hauri. The scale was then retested in the form presented in the Appendix, using a new set of 153 dreams collected in the same conditions as the first set, in a group of 8 healthy females. 


\section{RESULTS}

In the test of the first set of dreams, using pilot definitions, 'unreality' proved to be the most difficult characteristic to measure. The revision of the scale, with particular attention devoted to this term, led to an improved level of agreement ( $73 \%$ rising to $89 \%$ ). Similarly, "participation of the dreamer' and 'sensorium' yielded a poorer agreement than the other items of the scale. These items are concerned with features of the dream which are more difficult to appreciate and rate. Consequently, the raters were provided with more detailed definitions. The definitions given in the appendix led to an improvement in almost all other items, but the degree of enhancement of the agreement was smaller.

As we re-examined the material relating to the first test, it appeared desirable to make other modifications to the scale originally described. In this scale, all ratings had a positive range of from 1 to 6 points for the registration of an increasing intensity of the respective dream characteristics. In terms of our working definitions, point 6 appeared relatively rarely, except for item 7 . This point was subsequently removed and the scale restricted to cover points 1 to 5 . Furthermore, it proved easier to define 5 , rather than 6 , clear anchor points.

A difficulty with the item 'pleasantnessunpleasantness' (Hauri's item 3) arose from our decision to score the dream as a whole (see discussion). Contradictory feelings were reported to occur not infrequently in the same dream, the dreamer being frightened by one part of the dream and pleased by another. In our material, this phenomenon was encountered in $13 \%$ of REM contents. Accordingly, item 3 of Hauri's original scale was divided into two separate items - 'pleasantness' and 'unpleasantness'. The use of two factors clearly entails a loss of orthogonality, since 'pleasantness' and 'unpleasantness' are negatively correlated (P. Hauri, personal communication). However, in this particular case, it appeared to us important to retain more of the data despite this loss.

In the original scale, item 7 ('perceptualconceptual') and item 8 ("time of reference in the dreamer's life') were rated by the subject. In order to gain in homogeneity, we chose to have these items scored by the judges in the same way as the other items, provided that the interview furnished some clarification after the spontaneous report. The definitions of these items were modified accordingly.

Item 1 of the original scale took two dimensions into account, namely 'unreality' and 'intensity'. While these dimensions are roughly parallel, they are not exactly so, and this may sometimes result in a conflicting situation. It was therefore proposed to emphasize only the dimension of 'unreality'. In Hauri's original scale, the variable most loaded on the first factor was 'imagination', whereas 'distortion' was loaded slightly less (Hauri et al. 1967, Table 1). However, 'imagination' can be expected to be more dependent than 'bizarreness' on the choice of words by the dreamer. It follows that 'imagination' could be more influenced by the cultural and educational level of the subject. This consideration influenced our choice, although it is at present an assumption which calls for verification. Finally, it appeared to us unnecessary, for practical use, to restrict 'sexuality' to 'heterosexuality', and 'physical aggression' to aggression displayed by the dreamer himself, although in the work of Hauri these limitations were justified for statistical reasons, particularly in order to decrease the correlation with other items.

The scale of Hauri et al. (1967) with the small modifications proposed, is as follows:

(1) How unreal is the dream?

(2) How much is the dreamer, as a participant, actively trying to influence what is going on?

(3) How pleasant is the dream?

(4) How unpleasant is the dream?

(5) How much verbal aggression is there?

(6) How much physical aggression is there?

(7) How much sexual activity is there?

(8) How much of the dream is perceptual?

(9) With what time of the dreamer's life is the manifest content of the dream associated?

Table 1 shows the percentage of agreement for this modified scale between two scorers under two conditions, namely for perfect agreement only and for agreement allowing one point difference between the two judges. In the first of these conditions, six percentages (for items 3,4 , $5,6,7$ and 9) are reasonably high, and three are lower (for items 1, 2 and 8). However, the disagreement for these items is not high, since if one allows a one point difference between the two 
TABLE 1

PERCENTAGE OF AGREEMENT AND WEIGHTED KAPPA FOR THE RATING OF 153 DREAMS BY TWO SCORERS

\begin{tabular}{|c|c|c|c|}
\hline Items & $\begin{array}{l}\text { Perfect } \\
\text { agree- } \\
\text { ment } \\
\text { only } \\
(\%)\end{array}$ & $\begin{array}{l}\text { One } \\
\text { point } \\
\text { differ- } \\
\text { ence } \\
\text { allowed } \\
(\%)\end{array}$ & $\begin{array}{c}\text { Weighed } \\
\text { Kappa }\end{array}$ \\
\hline $\begin{array}{l}\text { 1. Unreality } \\
\text { 2. Participation of the } \\
\text { dreamer } \\
\text { 3. Pleasantness } \\
\text { 4. Unpleasantness } \\
\text { 5. Verbal aggression } \\
\text { 6. Physical aggression } \\
\text { 7. Sexuality } \\
\text { 8. Sensorium } \\
\text { 9. Time of reference in } \\
\text { the dreamer's life }\end{array}$ & $\begin{array}{l}57 \\
67 \\
63 \\
81 \\
90 \\
91 \\
55\end{array}$ & $\begin{array}{l}96 \\
89 \\
88 \\
96 \\
97 \\
98 \\
98\end{array}$ & $\begin{array}{l}0.554 \pm 0.040 \\
0.574 \pm 0.043 \\
0.562 \pm 0.048 \\
0.576 \pm 0.047 \\
0.704 \pm 0.046 \\
0.584 \pm 0.089 \\
0.539 \pm 0.098 \\
0.551 \pm 0.045\end{array}$ \\
\hline
\end{tabular}

Items are those given in the text, modified from Hauri $e t a l$. (1967). Scoring has been made using the definitions given in the appendix. All Kappa values are significant for $P<0.005$.

judges, the percentage of agreement rises approximately to the same level as for other items.

\section{DISCUSSION}

A central issue is the definition of the unit to be scored. One may choose more or less small units such as phrases or words leading, for instance, to the calculation of one score per word (Whitman et al. 1961). While it is relatively simple to define units in written language, it is much more difficult to do so in the particular spoken language of the dream-content, unless it is clear of any repetition, unfinished phrases or words, and all the hesitations which appear in the spoken language of a somewhat sleepy person. It is often almost impossible to see where a phrase begins and where it ends. For these reasons it appeared to us more convenient to score the entire dream as a whole, using the definitions given in the introduction.

However, this procedure may also lead to some difficulties. For instance, one single report may contain two 'dreams' in the commonly accepted usage of this word. The dreamer cannot always ascertain if he has experienced two separate 'dreams' or simply a change of scene in a single 'dream'. It is also not certain to what extent the judge can rely on the judgement of the dreamer on this point. In addition, two parts of the dream may be contradictory, at least in their manifest content.
It seemed to us a convenient procedure to focus on elements of the dream and to assess the entire dream by rating the element of maximum load. Dream elements may be defined as settings, characters, animals, objects, activities (what characters or animals are doing) and events (what occurs spontaneously to settings, characters, animals and objects of the dream). For factors 3 and 4 the feelings of the dreamer about the elements must be taken into account, and not the feelings which they elicit in the observer. It should be made clear that by the concept of element of maximum load we do not mean the element of central importance in the dream, which may be difficult to define, but the element of the dream giving a maximum rating. Thus, if one dream-character adopts a threatening attitude and in another part of the dream beats another character, then the dream must be scored 5 , since the threatening attitude, which in itself would qualify for a rating of 2 , is included within rating 5 . The number of occurrences of a given element in the dream is here not taken into account. If an element is of very minor importance its weight may be decreased. In other words, what is scored is the intensity of an element rather than its frequency. In addition, if an element does not appear in the dream itself, but is only quoted or reported, it is convenient to decrease its weight by one point. Thus, a murder actually occurring in the dream will be rated 5 in question 6; if this murder is only reported, it will be rated 4 .

This procedure also permits us to avoid the well-known pitfall in ordinal scales; whether, for example, on a 5-point scale on which a threatening attitude is rated at 2 and a murder at 5 , a murder should equal 2.5 occurrences of the threatening attitude. In this situation, we propose to score as 2 a dream containing one or several occurrences of a threatening attitude, and as 5 a dream containing a murder.

In difficult situations, as for instance when an awakening protocol seems to contain two dreams, a convenient procedure consists of scoring the two dreams separately, and then taking only the higher of the two ratings of each dimension. In this way a single rating is obtained for the protocol in each dream dimension.

The concept of maximum load rating is readily applicable to the majority of items. For items 1,2 and 8 , however, it cannot be taken in 
an absolute sense and the combination of elements, as well as the context of the dream, must also be taken into account. While individual elements in the dream may lend themselves to the procedure, their juxtaposition may prove to be impossible. Thus, factors $3,4,5,6,7$ and 9 can be scored with a maximum load rate, and factors 1,2 and 8 can be scored out of the total dream content.

The co-existence of unipolar and bipolar items also constitutes a potential difficulty. It makes it impossible to calculate a rough index of the dream by adding the ratings obtained for all items. This, however, could provide a simple classification of a set of dreams. In the scale under discussion, and with the modifications we have proposed, all items may be regarded as unipolar with respect to unreality, participation of the dreamer, pleasantness, unpleasantness, verbal aggression, physical aggression, sexuality, sensorium and the period of the time reference, each of them weighted from 1 to 5 inclusive.

Whether empty dream-content should be rated or not depends on the purpose of the experiment. It can follow on an awakening preceded by high variability of breathing (Shapiro et al. 1964) and may represent either a lack of mental activity or mental activity for- gotten in the wake of some active process. In order to avoid confounding these two extreme situations, a safe procedure is to discard both types of content (Hauri, 1975). It is generally difficult to distinguish, on the basis of the reports, true empty contents from forgotten ones.

Scoring decisions about dreams have to be taken in relation to a given point of reference which must be defined. In our case, the best available point of reference is the life of the dreamer himself. Therefore, the dream collection prccedure must include specific questions for every point in need of clarification. When this reference is not available, the scorer will have to make his decisions with respect to reality in the most general sense. For item 2, however, the context of reference is not the dreamer's life but the dream itself. The activity of the dreamer must be rated partly with respect to the activity of the other characters of the dream, and partly by the influence of this activity on the course of the dream.

We are grateful to Professor P. Hauri for reviewing our manuscript and for his very useful comments. We would also like to acknowledge the skilled technical assistance of Mrs Larrieu and Mr Barraud.

\section{APPENDIX}

ITEM 1

(1) Rational content corresponding to the reality of the subject without any improbable or impossible element. The dream generally contains very ordinary elements drawn from the subject's daily life. The elements appear as they are in reality. The content may be poor, generally poorer than in the following categories. It involves one single scene, unless the subject says that two different dreams are involved. There is no change of setting.

(2) Rational and possible content, but with some improbable elements, that is elements of low probability in reality but not impossible. However, the difference from reality is not very great. The dream may involve one or other of the following peculiarities: change of place or surroundings without any transition; some peculiarities of the setting, characters, things, animals, which are possible, but do not correspond to reality (e.g. larger room, differently arranged, dog of bizarre colour, character wearing improbable clothes); behaviour or activity which, without being altogether impossible, does not fit the character's usual behaviour in reality; association of characters and places, of attitudes or actions in various places which are improbable.

(3) Content mixing rational and improbable elements. The improbable elements prevail over the real elements. The places, characters, or objects are different from reality, without being absurd or materially impossible. The subject may have doubts about the elements' identity. Very improbable association of elements.

(4) Content mixing rational and impossible elements, e.g. transformation of characters, of places or objects; sudden appearances or disappearances; hybrid objects or places; association of several places, characters or dissimilar objects which are never associated in reality; a succession of activities which do not normally foilow one another; multiple identity, animal-plants, etc.

(5) Wholly impossible and unreal content. The dream's texture and its main elements are absurd, e.g. a mixture of settings, characters and imaginary objects ('an arm at the door, without the rest of the body'); intrusion of places or things, with no justification of purpose. 
ITEM 2

(1) Dreamer absent, unmentioned in the dream content. The action takes place without him and may be minimal.

(2) The dreamer is implicitly or explicitly mentioned in the dream. He is present in the dream, but does not manifest himself by his action or by what he says ('I know I was present, but I was only watching'). He is passive, undergoing an experience. He is an observer of what is going on or of what the other characters are doing, but he, himself, says practically nothing and hardly acts ('I was lying still and a lot of people were moving around').

(3) The dreamer is present in the dream but says and does relatively little. The dream's action is little influenced by what he says or does. He may or may not be concerned by the action of the dream which is carried on by the other characters.

(4) The dreamer is active. He converses with the other characters; he acts and moves, and by his action affects the events of the dream.

(5) The dreamer is very active. His actions or words clearly dominate the scene. He controls events and plays a dominant role with regard to the other characters who are dim figures in the background.

\section{ITEM 3}

(1) Neutral.

(2) Vaguely pleasant. Presence of elements described as agreeable by the dreamer. Vague aesthetic satisfaction. Relaxed atmosphere.

(3) Satisfaction felt from some successful action. Gaiety, gala atmosphere. Amusing event. Aesthetic satisfaction. Elements described as very beautiful. Jokes. Presence in the dream of attractive characters.

(4) Definitely pleasant, very amusing. Very cheerful situations, laughter; situation felt as comic in the dream. Real aesthetic satisfaction.

(5) Very pleasant. Feeling of happiness or exaltation. Intense satisfaction.

\section{ITEM 4}

(1) Neutral.

(2) Vaguely unpleasant. Presence in the dream of elements described by the dreamer as ugly, unaesthetic,

dirty. Atmosphere somewhat tense; vague or doubtful anxiety.

(3) Somewhat unpleasant. Unsuccessful attempt to do something. Frustration. Something that does not work as it should. Events that are not going as they should. Sad atmosphere. Presence of very unaesthetic elements. Disagreeable characters. Danger. Slight fear or anxiety (for instance, fear of failure).

(4) Definitely unpleasant. Embarrassing situation. Sadness, tears. Marked discordance. Positive fear or anxiety.

(5) Very unpleasant or terrifying. Despair. Disgusting or repulsive elements. Fear or intense anxiety.

\section{ITEM 5}

(1) No verbal aggression.

(2) Words whose aggressive character is uncertain. Slightly unfavourable attitude towards somebody. Slight disagreement between two or several characters. Slight criticism of something.

(3) More clearly aggressive words. Contempt expressed against somebody. Open criticism. Opposition to something. Definite disagreement between two or more characters. The aggression, however, is expressed in a relatively subtle manner.

(4) Openly aggressive words or conversation, quarrel between characters. Very pronounced opposition to something.

(5) Violent anger, intense dispute, verbal aggression expressed brutally.

\section{ITEM 6}

(1) No physical aggression.

(2) Gestures or behaviour whose aggressive character or purpose are uncertain. Vague threats in the expression or attitudes of people. Characters making fun of somebody, or planning to play tricks on someone. Blows received or given, whose aggressive character is uncertain.

(3) Behaviour indicating frankly aggressive or threatening intentions. Activity designed to keep somebody from doing something; physical opposition to somebody or something, the violent character of which is unclear. 
(4) Aggressive behaviour, some blows exchanged, abrupt gestures, jostling, physical coercion.

(5) Attacks, scuffles, fights, characters struggling, use of weapons. Injuries resulting from aggressive behaviour of one or more characters. Murder (excluding accidents).

\section{ITEM 7}

(1) No sexual element.

(2) Vague or uncertain sexual elements. Places or situations that may have a romantic or sexual significance (e.g. dancing). Description of the secondary sexual characters of one or more characters (e.g. girl with beautiful hair). Meeting of people having sentimental ties or in somewhat ambiguous situations. Such feelings as jealousy or vague attraction. The simple meeting of characters of different sexes is not sufficient to rate here if the situation is neither ambiguous nor with possible romantic implication.

(3) Gestures with a sentimental or sexual significance (e.g. kissing somebody). Particular aspects of clothing that may have a sexual significance. People lightly dressed in circumstances where it would not be expected (e.g. experimenter wearing a bathing suit). Romantic feelings, tenderness.

(4) Presence of sexual organs, of prostitutes. Beginning of a frankly sexual activity, but not consummated. Petting. Nude characters. Attraction of directly sexual or romantic nature.

(5) Behaviour or gestures with a very obvious sexual significance. Sexual intercourse, sexual excitement, open desire.

\section{ITEM 8}

(1) Thoughts, ideas or pure concepts, without sensory elements. There are no pictures, no colours, no sound.

(2) Thoughts or ideas combined with occasional and uncertain sensory elements, noises or pictures. The sensory elements are isolated, vague, colourless, without details (e.g. a talk without the characters being visible).

(3) Some meagre and moderate sensory elements which may or may not be accompanied by thoughts. They involve no details or very few; sometimes an outstanding detail may have been noted.

(4) Definite sensory elements, but involving few or no colours. They may involve some sounds. The subject may give some details, but the whole appears somewhat dull.

(5) Intense sensory elements. There are several brilliant colours, many sounds. The subject can give numerous and exact details about the elements of the dream, such as the clothing of the characters, the arrangement of rooms, etc.

\section{ITEM 9}

(1) The dream refers to a very recent period in the subject's life (a few hours). One has to rate here all references to the experimental situation, such as the appearance of one of the experimenters.

(2) The dream contains elements related exclusively to an event experienced by the subject the day before.

(3) Without the temporal reference explicitly mentioned, but situated in the present life of the subject (e.g., in his family situation or in his current professional activity).

(4) Located in the earlier life of the subject (childhood, previous job, his former school), or situated in his present life, but involving early elements such as characters when they were younger, buildings or places that have changed, that no longer exist in reality or which the subject no longer visits. One will rate here, for instance, a dream in which the subject sees himself at his present job, but is doing this work in a building where he went to school.

(5) The dream is located in a remote, historical time, prior to the subject's life, or involving elements of past time ('I was at the clinic as it probably looked 40 or 50 years ago').

\section{REFERENCES}

Cohen, J. (1960). A coefficient of agreement for nominal scales. Educational and Psychological Measurement 20 (1), 37-46.

Cohen, J. (1968). Nominal scale agreement with provision for disagreement or partial credit. Psychological Bulletin 70 (4), 213-220.

Fleiss, J. L., Cohen, J. \& Everitt, B. S. (1969). Large sample standard errors of Kappa and weighted Kappa. Psychological Bullerin 72 (5), 323-327.
Foulkes, D., Spear, P. S. \& Symonds, J. D. (1966). Individual differences in mental activity at sleep onset. Journal of Abnormal Psychology 71 (4), 280-286.

Gottschalk, L. A., Gleser, G. C., Springer, K. J., Kaplan, S. M., Shanon, J. \& Ross, W. D. (1960). Effects of perphenazine on verbal behaviour patterns. Archives of General Psychiatry 2, 632-639.

Hall, C. \& van de Castle, R. (1966). The Content Analysis of Dreams. Appleton: New York.

Hauri, P. (1975). Categorization of sleep mental activity for psycho-physiological studies. In Experimental Study of 
Human Sleep: Methodological Problems (ed. G. C. Lairy and P. Salzarulo), pp. 271-281. Elsevier: Amsterdam.

Hauri, P., Sawyer, J. \& Rechtschaffen, A. (1967). Dimensions of dreaming: a factored scale for rating dream reports. Journal of Abnormal Psychology 72 (1), 16-22.

Kramer, M., Winget, C. \& Roth, T. (1975). Problems in the definition of REM dreams. In Sleep 1974, 2nd European Congress on Sleep Research, Rome 1974 (ed. P. Levin and E. P. Koella), pp. 149-156. Karger: Basel.

Molinari, S. \& Foulkes, D. (1969). Tonic and phasic events during sleep: psychological correlates and implications. Perceptual and Motor Skills 29, 323-368.
Shapiro, E., Goodenough, D. R., Biederman, I. \& Sleser, I. (1964). Dream recall and the physiology of sleep. Journal of Applied Physiology 19, 778-783.

Sheppard, E. (1969). Dream-content analysis. In Dream Psychology and the New Biology of Dreaming (ed. M. Kramer), pp. 225-254. Charles C. Thomas: Springfield, III. Whitman, R. M., Pierce, C. M., Maas, J. W. \& Balridge, B. (1961). Drugs and dreams II : Imipramine and prochlorperazide. Comprehensive Psychiatry 2, 219-226. 